\title{
Survey Extent Antibiotics and Others Pediatric-intoxication Affected Pediatric-public-health in Saudi-society
}

\author{
Sherifa Mostafa M. Sabra ${ }^{*}$, Abdulrahman Salem K. Alanazi ${ }^{2}$, Abdullah Ibrahim R. Alanazi ${ }^{3}$ and Badr Mohammed K. Alenezi ${ }^{4}$ \\ ${ }^{1}$ Senior Const., Asst. Prof., Dr., Microbiology, Technology and Science Dept., Ranyah College, Taif University, KSA. \\ 2, 3, 4 Pharmacy Student, Pharmacy College, King Saud University, Riyadh, KSA. \\ *Corresponding Author: Sherifa Mostafa M. Sabra. Asst. Prof., Dr., Microbiology, Technology and Science Dept., Ranyah University College, \\ Taif University, KSA \\ Received date: December 13, 2020; Accepted date: December 15, 2020; Published date: February 01,2021 \\ Citation: Sherifa M. M. Sabra, Abdulrahman S. K. Alanazi, Abdullah I. R. Alanazi and Badr Mohammed K. Alenezi (2021) Survey Extent Antibiotics \\ and Others Pediatric-intoxication Affected Pediatric-public-health in Saudi-society. J, Biotech.and Bioprocessing 2(2); DOI: 10.31579/2766-2314/017 \\ Copyright: (C) 2021, Sherifa Mostafa M. Sabra, This is an open access article distributed under the Creative Commons Attribution License, which \\ permits unrestricted use, distribution, and reproduction in any medium, provided the original work is properly cited.
}

\begin{abstract}
This paper was for "Survey extent antibiotics (As) and others pediatric-intoxication (PI) affected pediatric-publichealth (PPH) in Saudi-society (SS)". That showed for age (0-2) year (yr) un-aware parents $70 \%$ for drugsintoxication (DsI) symptoms. Parents $69 \%$ using colored and smelled attractive materials, drug $78.2 \%$ was used for kid without medical prescription (MP). For age (3-6) yr, 56.8\% used Ds of non-MP. Parents $73.1 \%$ used their own medicines in front of their kids. In age (7-13) yr, PI showed 5\%, it was by parents used same drug for kids represented $45.4 \%$. It was $20.6 \%$ noticed new symptoms on their kids and did not go to pediatric Doctor Clinic. PI for age (0-2) yr was $4.3 \%$, AsI was $16.7 \%$ that of DsI cases in SS. It was for age (3-6) yr with drugs and other equivalent $11.4 \%$. AsI was $43.4 \%$ and non-DsI $57.7 \%$, revealed $21.2 \%$ and non-AsI was $21.1 \%$. PI for age (7-13) yr were $54.3 \%$ of cases of DsI. That $17.2 \%$ was of the AsI cases, One-third of the DsI were considered high, $37.1 \%$ non-DsI. That concluded the parents' awareness and education to improve PI reduction. As well they must do not leave different materials closely to kids, to make this difficult to obtain and difficult to use. They must teaching kids the seriousness effects of as and others on their health that will keep PPH in SS. Must recommended "Health Education" for parents to know PI dangerous, decrease PI through MP, consulting Pediatric Doctor, keep chemical materials and drugs away from kids.
\end{abstract}

Keywords: antibiotics, pediatric-intoxication, pediatric-public-health, saudi-society, drugs-intoxication, medical prescription

\section{Introduction}

kids parents must brought MP as ideal TT, there was a departure from TT by buying medications from pharmacy without MP [1], in KSA, during 2013, it found the possibility for purchased drugs from pharmacies without MP [2], in same year at Riyadh, non-MP among Saudi kids treatments was $43.6 \%$ of population [3]. In King Abdullah Int. Med. C., during 2015, the medications miss-used were $57.8 \%$ in PS [4]. Kids parent's knowledge, beliefs, behaviour, information sources, adherence, awareness and MP regarding doctors were seriously affected PI [5]. Their geographical background was associated with them and their kids medications use and others materials, that was affected by parents background, education level and culture [6]. The reasons of high prevalence PI were complex; and were in several contributing factors counting kids parents cultural factors, behavioral personality, socioeconomic status, and education level [7].

PI in Qassim Region at 2003, was 39\% in kids age $\leq 5$ yr [8], in Abha city, after one yr affected more in age (2-4) yr [9], while in Tafila, after two yr the more affected were in age (1-5) yr [10]. In King Khalid University Hospital, during 2011, it was $68 \%$ for age (0-12) yr [11]. In
Dammam after three yr, it was more in age (1-7) yr as $74.8 \%$ [12], and in $\mathrm{Al}$ Majmaah region, it was $74.4 \%$ in age (1-6) yr [13]. In Western KSA, after one year, it was $44.2 \%$ for less than 12 yr [14]. In Riyadh, during 2017, was in under age two yr [15], while $\mathrm{MOH}$ resulted 53.3\% in age (04) yr [16]. DsI in Qassim, during 2003, was 42.1\% [8], but in Abha after one year, it was $72 \%$ [9], so after two yr it was $55 \%$ at Tafila [10]. King Khalid University Hospital, Riyadh, at 2011 was $76.7 \%$ [11], in Dammam, at 2014 was $63.2 \%$ [12], while after one yr in Western Saudi Arabia was 92.2\% [16]. In 2017 was 1.3\% [17]; and in Riyadh, after one yr was 70\% [15]. Non-DsI in Qassim at 2003 was 57.9\% [8], after one yr in Abha was 28\% [9], then after two yr in Tafila was 45\% [10]. King Khalid University Hospital, Riyadh, at 2011 was $6.8 \%$ [11], but after four yr in Western Saudi Arabia was 7.8\% [14]. In KSA at 2017 was 56.6\% [17], after one yr in King Khaled University Hospital Riyadh was 29\% [15]. AsI resulted toxicity associated by higher morbidity and morbidity and extended hospitalization [18]. In Tafila, at 2006 was 10.5\% [10], but at 2016, in Saudi population was (41-92\%) [7]; and $\mathrm{MOH}$, after one year recorded $4.3 \%$ [16].

The aim for this work was carried out in a "Survey Methodology", since PI by drugs and others substances which affected PPH. Therefore, the 
research was focused on the reasons helped PI. The reasons included the role of kid's parents in non-MP purchase, methods of medications keeping, expiration date, and medications recurrence and did not follow the Pediatric Doctor's Consultation in treatment and duration. The others materials were not kept as in safe places and were very ease of access and use by kids. Other factors in PI by substances, which were as the presence of PI substances characters as; attractive colors, odours, an ease way of reaching and opening. That were affected PPH in SS, so this paper would excreted some benefits.

\section{Methodology}

1. Chosen method: "Survey Methodology" was studies sampling of individual units from population [20-21].

2. Preparation questionnaires: "Reviewed Essential" was of study objectives, (Table 1-3) [22].

\begin{tabular}{|c|c|c|c|}
\hline \multirow[t]{2}{*}{ *No } & \multirow[t]{2}{*}{$* Q$ title } & \multicolumn{2}{|c|}{ Answer } \\
\hline & & Yes & No \\
\hline 1 & Has your child ever had a drug poisoning? & & \\
\hline 2 & Do you know the symptoms of drug poisoning? & & \\
\hline 3 & Do you consult your doctor or pharmacist about the appropriate dose for your child's medication? & & \\
\hline 4 & Do you keep medicines in the appropriate environment? & & \\
\hline 5 & During breastfeeding, do you consult your pharmacist or doctor before using the medicine? & & \\
\hline 6 & Are you committed to giving your child medication on time? & & \\
\hline 7 & Do you keep medicines out of reach of your child? & & \\
\hline 8 & Do you use shampoo or soap of color and attractive scent for children? & & \\
\hline 9 & Do you use non-prescription medicines for your child? & & \\
\hline 10 & If the answer to the first question if its yes, What substance that caused poisoning your child? & & \\
\hline & *Yr: Year, *Q: Question, *No: Number & & \\
\hline
\end{tabular}

Table 1. Questionnaires for children in age (0-2) *yr

\begin{tabular}{|c|c|c|c|}
\hline \multirow[t]{2}{*}{ *No } & \multirow[t]{2}{*}{${ }^{*} Q$ title } & \multicolumn{2}{|c|}{ Answer } \\
\hline & & Yes & No \\
\hline 1 & Does your child take the medication, or does the mother or father, do it? & & \\
\hline 2 & Has your child been exposed to drug poisoning? & & \\
\hline 3 & If your child is poisoned, what is the substance of the poisoning? & & \\
\hline 4 & Do you ask your doctor or pharmacist about appropriate dose of medication for your child? & & \\
\hline 5 & When you use more than one medicine for your child, do you tell doctor and pharmacist? & & \\
\hline 6 & Do you keep medicines away of your children? & & \\
\hline 7 & Do you use non-prescription medicines for your child? & & \\
\hline 8 & Do you take your medicines in front of your children? & & \\
\hline 9 & Do you tell your child that the medicine is a kind of candy? & & \\
\hline 10 & Do you commit to giving the medicine to your child on time? & & \\
\hline 11 & Are you looking for expired medicine? & & \\
\hline 12 & Do you get rid of the medicine safely? & & \\
\hline & *Yr: Year, *Q: Question, *No: Number & & \\
\hline
\end{tabular}

Table 2. Questionnaires for children in age (3-6) *yr

\begin{tabular}{|c|c|c|c|}
\hline \multirow[t]{2}{*}{$* N o$} & \multirow[t]{2}{*}{ *Q title } & \multicolumn{2}{|c|}{ Answer } \\
\hline & & Yes & No \\
\hline 1 & Has your child been exposed to drug poisoning? & & \\
\hline 2 & Do you put your medicines in safe places away from the sun and high temperatures? & & \\
\hline 3 & Do you always look at the date of validity of your medicine? & & \\
\hline 4 & $\begin{array}{l}\text { When your child is exposed to a similar symptoms to his older brother. Do you give him the same medicine's } \\
\text { brother without consulting your doctor? }\end{array}$ & & \\
\hline 5 & When you finish eating your medicine do you bring it back to its original packaging? & & \\
\hline 6 & When your child exposed drug poisoning do you go quickly to tell your doctor? & & \\
\hline 7 & Does your child take your medication by the time the doctor told you? & & \\
\hline 8 & Do you get rid of your medication safely when you finish it? & & \\
\hline 9 & When your child takes a dose of his medicine and does not get the benefit, does he repeat this dose? & & \\
\hline 10 & When you notice new symptoms on your child after taking medicine Do you go to the doctor directly? & & \\
\hline & *Yr: Year, *Q: Question, *No: Number & & \\
\hline
\end{tabular}

Table 3. Questionnaires for children in age (7-13) *yr

3. Addition on line: "Online Surveys" was depending on content and length of questionnaire [23].

4. Collection results: "Look at research questions, filtered the results, recorded numbers" [24].

5. Investigation data: "Simple Excel Program" which formed the consequences [25]. 


\section{Results and discussion}

\begin{tabular}{|l|c|c|c|c|c|c|c|c|l|}
\hline$* \boldsymbol{Q} *$ No & $\mathbf{Q 1}$ & $\mathbf{Q 2}$ & $\mathbf{Q 3}$ & $\mathbf{Q 4}$ & $\mathbf{Q 5}$ & $\mathbf{Q 6}$ & $\mathbf{Q 7}$ & $\mathbf{Q 8}$ & $\mathbf{Q 9}$ \\
\hline Positive & $4.3 \%$ & $30 \%$ & $94.5 \%$ & $94.2 \%$ & $93.5 \%$ & $88.2 \%$ & $96.2 \%$ & $69 \%$ & $78.2 \%$ \\
\hline Negative & $95.7 \%$ & $70 \%$ & $4.5 \%$ & $5.8 \%$ & $6.5 \%$ & $11.8 \%$ & $3.8 \%$ & $31 \%$ & $21.8 \%$ \\
\hline \multicolumn{8}{|c|}{$*$ PI: Pediatric intoxication, *Yr: Year, *Q: question, *No: Number } \\
\hline
\end{tabular}

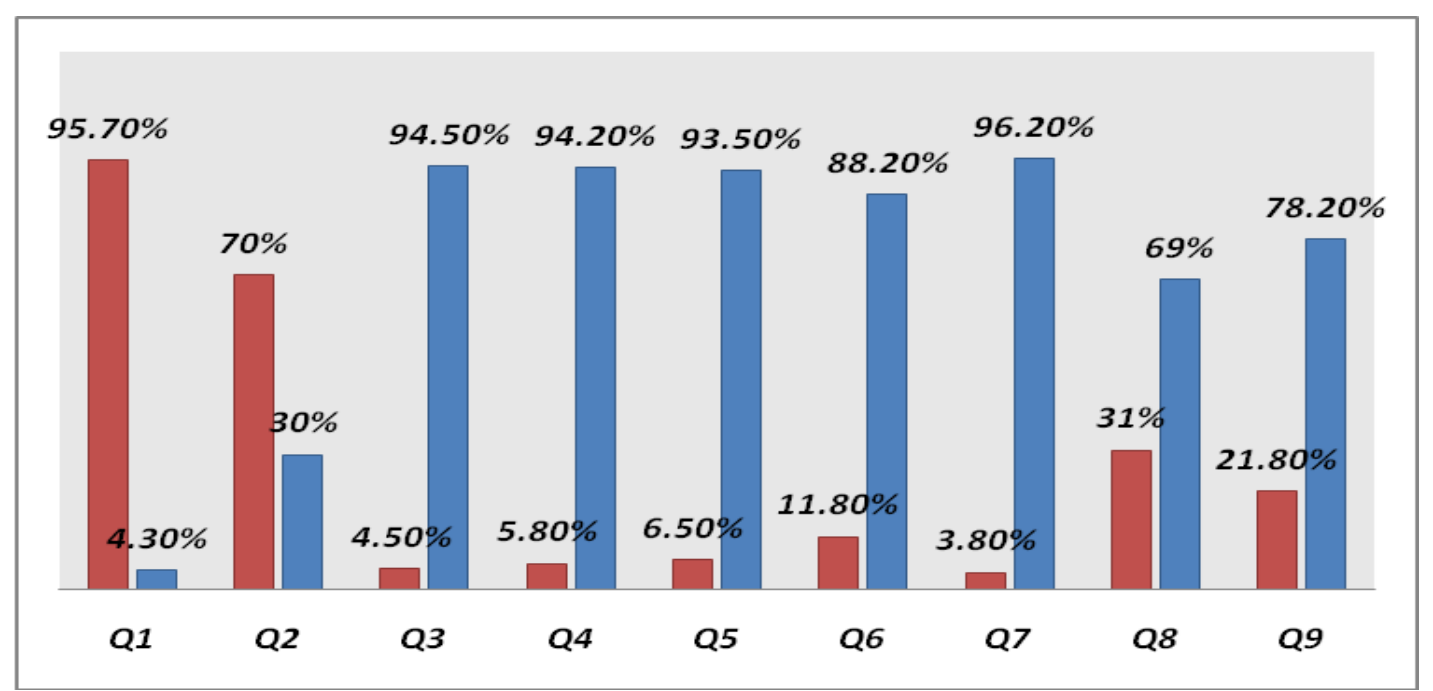

Table 4 and Diagram 1. Prevalence of *PI in age (0-2) *yr

Table 4 and diagram 1 showed prevalence of PI in age (0-2) yr, the results showed the participants were 633. Q2 showed large percentage of un-aware parents $70 \%$ for DsI symptoms, which affected the speed of PI response to the condition and increased the risk of exacerbation [8-17]. Q8 showed a significant percentage of parents $69 \%$ using colored and smelled attractive soap or shampoo to the kids and none presented in safe places and ease to open, which may lead to kids trying to swallow [8-14]. Q9 showed large proportion of drug 78.2\% was used for kid without MP, pediatric Doctor Consultation, so caught leading to DsI [8-17]. Q10 showed the most PI materials as fast food, antibiotic, insecticide, clorox, fevadol, food poisoning, antitussive, candy, sodium, eggs and propanol [8-16].

\begin{tabular}{|c|c|c|c|c|c|c|c|c|c|c|c|c|}
\hline${ }^{*} Q * N o$ & $Q 1$ & $Q 2$ & Q3 & $Q 4$ & $Q 5$ & $Q 6$ & $Q 7$ & $Q 8$ & $Q^{9}$ & $Q 10$ & $Q 11$ & $Q 12$ \\
\hline Positive & & $92.9 \%$ & & $97.7 \%$ & $91 \%$ & $92.4 \%$ & $43.2 \%$ & $73.1 \%$ & $25.6 \%$ & $88.6 \%$ & $83.7 \%$ & $73.7 \%$ \\
\hline Negative & & $7.1 \%$ & & $2.3 \%$ & $9 \%$ & $7.6 \%$ & $56.8 \%$ & $26.9 \%$ & $74.4 \%$ & $11.4 \%$ & $16.3 \%$ & $26.3 \%$ \\
\hline
\end{tabular}

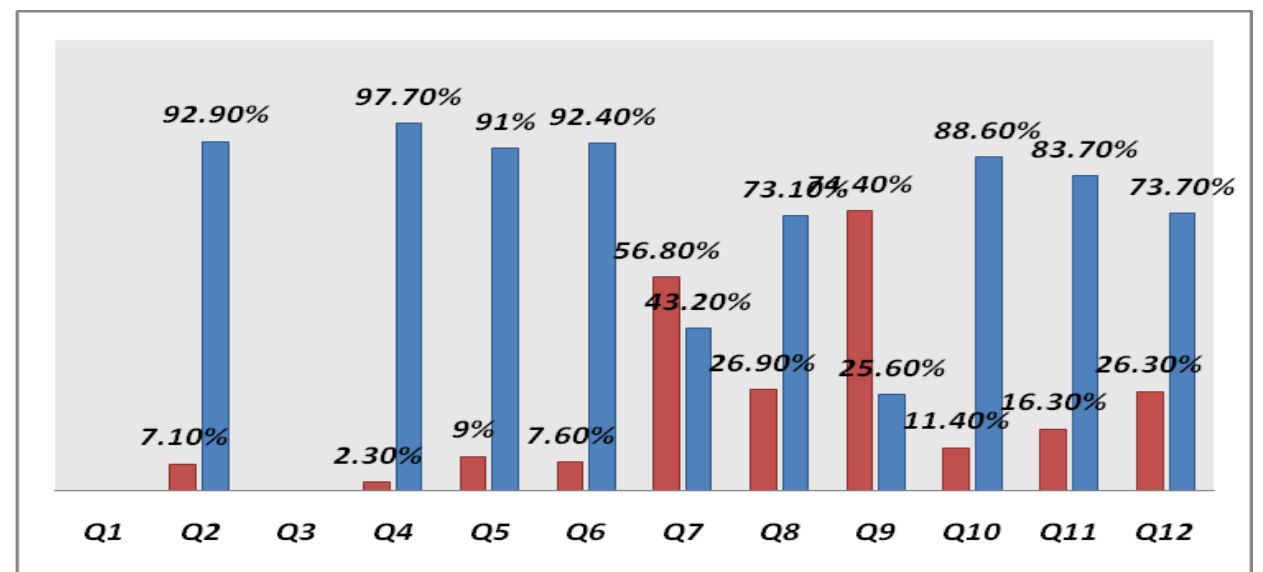

Table 5 and Diagram 2. Prevalence of *PI in age (3-6) *yr

Table 5 and diagram 2 showed prevalence of PI in age (3-6) yr, the participants were 687, Q1 showed who was give medication to kids as descending: Mother (395/687), Parents (168/687), Other (80/687), kids (25/687) and Father (19/687) [5-7]. Q2 was in the percentage of exposure of PI was high and the reasons are many [10-16]. Q3 showed the most PI materials as: chlorine, food poisoning, over dose of tranquilizer drug, collagen, overdose analgesic drug, panadol, fevadol, antibiotic, contraceptive pills, antipsychotic drug, ibuprofen, milk, eggs, expired medicine, expired date suppository, moldy bread, medicine not suitable for age, paracetamol [8-16]. The most important was through the Q7 was 
a large proportion $56.8 \%$ of the use of drugs for this age group of non-MP and this was undoubtedly a risk in terms of PI. Q8 found a large proportion of parents $73.1 \%$ used their own medicines in front of their kids and this exposes them to do the tradition of their parents and DsI [14].

\begin{tabular}{|l|c|c|c|c|c|c|c|c|c|c|}
\hline$* \boldsymbol{Q} *$ No & Q1 & $\mathbf{Q 2}$ & $\mathbf{Q 3}$ & $\mathbf{Q 4}$ & $\mathbf{Q 5}$ & $\mathbf{Q 6}$ & $\mathbf{Q 7}$ & $\mathbf{Q 8}$ & $\mathbf{Q 9}$ & $\mathbf{Q 1 0}$ \\
\hline Positive & $5 \%$ & $93.6 \%$ & $79.3 \%$ & $45.4 \%$ & $81.4 \%$ & $90.8 \%$ & $83.7 \%$ & $66.8 \%$ & $11.4 \%$ & $79.4 \%$ \\
\hline Negative & $95 \%$ & $6.4 \%$ & $20.7 \%$ & $54.6 \%$ & $18.6 \%$ & $9.2 \%$ & $16.3 \%$ & $33.2 \%$ & $88.6 \%$ & $20.6 \%$ \\
\hline \multicolumn{8}{|c|}{$*$ PI: Pediatric intoxication, *Yr: Year, *Q: question, *No: Number } \\
\hline
\end{tabular}

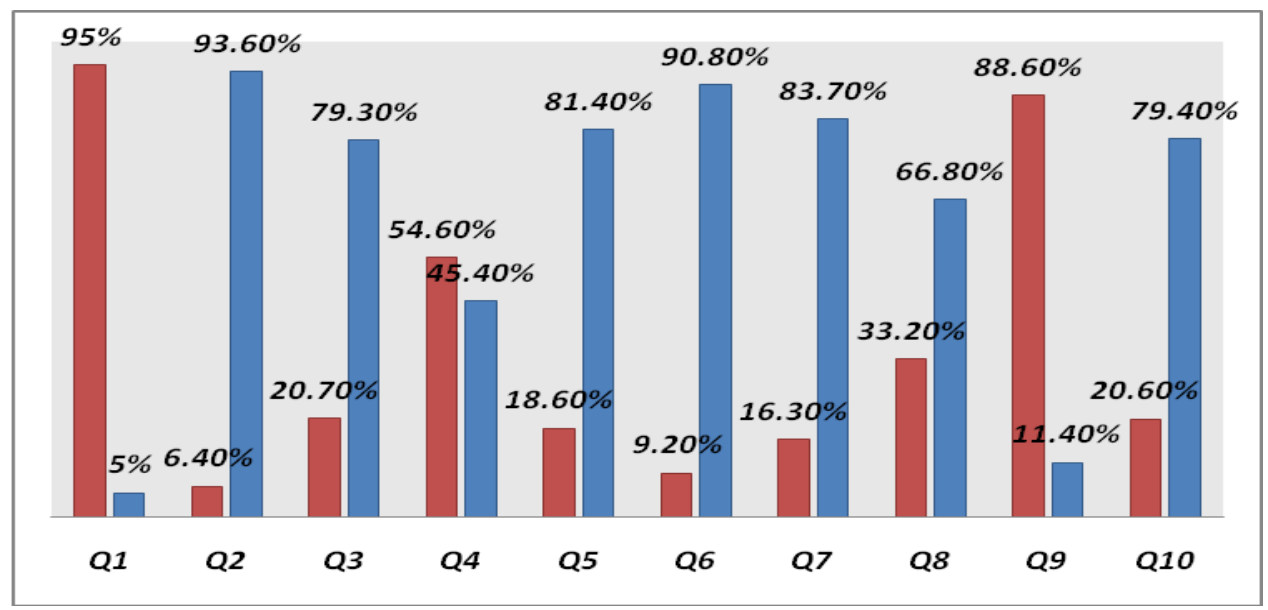

Table 6 and Diagram 3. Prevalence of *PI in age (7-13) *yr

Table 6 and diagram 3 showed prevalence of PI in age (7-13) yr, the participants were 699, Q1 was yes, the substance have you been as PI by: fast food, fevadol, chocolate, antibiotic, contraceptive pills, metoclopramide, DDAVP, chlorophenramin, dextromethorphan (for could flue), flagyl, clorox, asthma pills, and heart hole medication [8-16]. It was clear, that PI rate in Q1 showed rate of PI was 5\%, it indicated the awareness of parents and their understanding of these drugs and PI causes of PI [8-16]. Q4 reveled PI causes, it was that by parents when a son had the same symptoms as his older brother gave him the same medicine without pediatric Doctor Consultation and represented $45.4 \%$. This was a big mistake because of the differences between the two kids in health and speed and strength of response to the drug [1-7]. Q10 was about $20.6 \%$ of those who noticed new symptoms on their kids and did not rush to go to the pediatric Doctor clinic. These symptoms may be the result of an unknown drug I. It might cause problems for the kid if he did not go directly to pediatric Doctor Clinic [1-4].

\begin{tabular}{|c|c|c|c|}
\hline Age & \multicolumn{3}{|c|}{ Percent $* \%$} \\
\hline $0-2 * y r$ & \multicolumn{3}{|c|}{ Total $* P I=4.3 \%$} \\
\hline & \multicolumn{2}{|c|}{$* D I=31.6 \%$} & Non- $* D I=68.4 \%$ \\
\hline & $* A s I=16.7 \%$ & $\begin{array}{c}\text { Non- } * A s I= \\
83.3 \%\end{array}$ & \\
\hline \multirow[t]{3}{*}{ 3-6yr } & \multicolumn{3}{|c|}{ Total $* P I=11.4 \%$} \\
\hline & \multicolumn{2}{|c|}{$* D I=42.3 \%$} & Non- $* D I=57.7 \%$ \\
\hline & $* A s I=21.2 \%$ & $\begin{array}{c}\text { Non }-* A s I= \\
78.8 \%\end{array}$ & \\
\hline \multirow[t]{3}{*}{$7-13 y r$} & \multicolumn{3}{|c|}{ Total $* P I=5.0 \%$} \\
\hline & \multicolumn{2}{|c|}{$* D I=54.3 \%$} & Non $-* D I=45.7 \%$ \\
\hline & $* A s I=31.6 \%$ & $\begin{array}{c}\text { Non- } * A s I= \\
68.4 \%\end{array}$ & \\
\hline
\end{tabular}

Table 7. Prevalence of *PI types

Table 7 showed prevalence of PI types, the percentage for age (0-2) yr was low and did not exceed $4.3 \%$, and most cases of non-DI. The high percentage of parents who interested in giving treatment to the kid at the specified time and often mother consulted Pediatric Doctor before Ds uses, while breastfeeding the child led to reduced PI. The high rate of nonDI poisoning might be due to the high proportion of parents to use soap and shampoo, with attractive smell color and presented in un-safe places to kids and weakness of control from parents as it had the largest role. AsI was only $16.7 \%$ of cases of DsI for kids in SS [5-7]. It was the rate of infection for age (3-6) yr with drugs and other equivalent to $11.4 \%$, which is an average percent. It was also rate of AsI was $43.4 \%$ and the ratio of non-DsI was 57.7 as undoubtedly high rates. In this study of DsI, that found half of this percentage was infected with AsI as $21.2 \%$, while nonAsI was $21.1 \%$ [8-16]. Through this study, most of the PI cases for age 
(7-13) yr came from DsI. There were approximately $54.3 \%$ of cases of DsI. There was a relatively low proportion of non-DsI. There were $17.2 \%$ of the cases of AsI, which accounted for approximately one-third of the DsI and were considered high. There were also $37.1 \%$ by non-DsI [9-15].

\section{Conclusions}

Through the previous results, that found different materials had a significant impact on kids and often lead to PI. So the parents' awareness and education should therefore be improved to reduce PI, do not leave different materials close to the kid reach. Making the different materials difficult to obtain and difficult to use in addition to teaching kids the seriousness effects of different materials on them healthily, that will keep $\mathrm{PPH}$ in SS.

\section{Recommendation}

Must use "Health Education" for parents to know the dangerous of PI, also decrease PI through MP, consulting Pediatric Doctor, keep chemical materials and drugs away from kids.

\section{Acknowledgment}

All thanks for all persons helped in this paper.

\section{Future work}

That hope to investigate the "Health Education" of parents regarding PI, so it caught determine the shortfall that must avoided.

\section{Fundus}

It was on authors.

\section{Conflict}

There was no conflict to this research as it completed all aspects of the survey and did not contrary to any of the correct methods and there was no subject in the same way.

\section{References}

1. Hyun, Y., Hersh, L. and Namtu, (2013). Antimicrobial stewardship in pediatrics: How every pediatrician can be a steward. JAMA Ped. 167:859-866.

2. Khalil, H., Abdullah, W. and Khawaja, N. (2013). Self-prescribed antibiotics by Saudi patients as a routine self-management of dental problems. Life Sci. J., 10:1939-1942.

3. Alanazi, A., Almudhaibery, F. and Almamary, A., (2013). Non prescribed antibiotics consumption in children in Riyadh city, Saudi Arabia. J. Pharma. Biomed. Sci., 29:806-813.

4. Alanazi, Q., Aljeraisy, M. and Salam, M., (2015). Prevalence and predictors of antibiotic prescription in an emergency department, central of Saudi Arabia. Drug Health Care and Patient Safety. 7:103-111.

5. Arwa, A., Xiang-Yu, H. and Cameron, H., (2013). Assessing the overuse of antibiotics in children in Saudi Arabia: Validation of the parental perception on antibiotics scale (PAPA scale). Health and Quality of Life Outcomes. 11:39.
6. Arwa, A., Xiang-Yu, H., Jiandong, S., Abdullah, Y., and Cameron, H., (2015). The parental use of antibiotics in children in Saudi Arabia. Epidem. (Sunnyvale), 5(3).

7. Abdul Rahman, A., Rana, H., Noufa, A. and Abdul Rahman, A., (2016). Misuse of antibiotic: A systemic review of Saudi published studies. Cur. Ped. Res., 20(1\&2):169-173.

8. Moazzam, M., Al-Saigul, A., Naguib, M. and Al Alfi, M., (2009). Pattern of acute poisoning in Al Qassim Region: A surveillance report from Saudi Arabia, 1999-2003. Eastern Mediterranean Health J., 15(4):1005-1010.

9. Mohammed, A., (2004). Pattern of childhood poisoning in Abha city, Southwestern Saudi Arabia. J. Family Comm. Med. 11(2).

10. Hussein, A. and Ahmed, M., (2006). Childhood accidental poisoning in Tafila. Iran. J. Ped., 17(1):23-26.

11. Ahmed, A. and Fayssal, F., (2011). Pattern and determinants of poisoning in a teaching hospital in Riyadh, Saudi Arabia. Saudi Pharma. J., 19(1):57-63.

12. Ahmed, R. and Maha, K., (2014). Pattern of pediatric toxicity in Saudi Arabia-Eastern Province (Incidence, demographics and predisposing factors). Ped. Ther. 5:1.

13. Zeinab, A. and Badar, A., (2014). Pattern of acute poisoning in Al Majmaah region, Saudi Arabia. Am. J. Clin. Exp. Med., 2(4):7985.

14. Bakhaidar, M., Jan, S., Farahat, F., Attar, A., Alsaywid, B. and Abuznadah, W., (2015). Pattern of drug overdose and chemical poisoning among patients attending an emergency department, western Saudi Arabia. J. Com. Health, 40(1):57-61.

15. Sultan, A., Manal, A., Abeer, A., Nora, A., Bander, B. and Anas, A., (2017). The patterns of children poisoning cases in community teaching hospital in Riyadh, Saudi Arabia. Saudi Pharma. J., 26(1):93-97.

16. Sami, H., Alzahrani, A., Alqahtani, H., Fayssal, M., Mohammed, E. and Jamil, B., (2017). Drug poisoning and associated factors in western Saudi Arabia: A five-year retrospective chart review (2011-2016). Pak. J. Med. Sci., 33(5):1188-1193.

17. Alzahrani, S., Ibrahim, N., Elnour, M. and Alqahtani, A., (2017). Five-year epidemiological trends for chemical poisoning in Jeddah, Saudi Arabia. Ann. Saudi Med., 37(4):282-289.

18. Davey, P., Brown, E. and Charani, E., (2013). Interventions to improve antibiotic prescribing practices for hospital inpatients. Cochrane Database. Syst. Rev., 3(30).

19. http://george-beam.com/docs/AABSS.2013.Paper.pdf.2018

20. Shaughnessy, J., Zechmeister, E. and Jeanne, Z., (2011). Research methods in psychology ( $9^{\text {th }}$ ed.). New York, NY: McGraw Hill. pp. 161-175.

21. Mellenbergh, J., (2008). Chapter 9: Surveys. In H.J. Adèr \& G.J. Mellenbergh (Eds.) (with contributions by D.J. Hand), Advising on Research Methods: A consultant's companion (pp. 183-209). Huizen, The Netherlands: Johannes van Kessel Publishing.

22. https://en.wikipedia.org/wiki/Instructional_design.2018

23. https://academic.oup.com/intqhe/article/15/3/261.2018

24. http://Handbook-recommended-practices-questionnaire. 2018

25. http://edu/Biology statistics simple_using_Excel.pdf.2018 